\title{
A Conceptual Framework for Integrating Gamification in eLearning Systems Based on Instructional Design Model
}

\author{
https://doi.org/10.3991/ijet.v16i04.15693 \\ Hanaa Abdulraheem Yamani \\ Umm Al-Qura University, Makkah, KSA \\ Hayamani@uqu.edu.sa
}

\begin{abstract}
Gamification technology can significantly improve learners' motivation, so designing appropriate gamification can contribute to the acceptance of eLearning content by learners. This research attempts to analyze the concept of gamification and its components, types of players, and conditions for successful design by reviewing the literature. In addition, the research aims to investigate how the gamification design process can be used in education and what empirical effects are expected. The research also aims to propose a conceptual framework for gamification integration in eLearning systems based on the instructional design (ID) model. The methodology used in the identification of successful strategies and experiences is based on reviewing the literature that explains gamification, game strategies, and previous gamification frameworks. Examples and suggestions of gamification are included. The findings illustrate the potential techniques for applying gamification in eLearning systems, especially e-courses. The differences between Digital Games, gamebased learning, and gamification are discussed. The findings propose a conceptual framework for gamification integration in eLearning systems based on the ID Model. Gamification has been incorporated into the general phases of the ID model, namely, analysis, design, development, implementation, and evaluation. The findings help decision-makers and stakeholders at higher education institutions differentiate between games, game-based learning, and gamification integration into education and determine suitable ID models as conceptual frameworks for systematically delivering learning content through gamification.
\end{abstract}

Keyword—eLearning; Gamification; Game-Based Learning; Instructional Design; Higher Education

\section{$1 \quad$ Introduction}

Recent years have been characterized by continuous progress in information and communication technology (ICT) infrastructure. The data illustrates an uninterrupted growth of Internet usage with a rise in the number of Internet users worldwide. Saudi Arabia has invested heavily in developing ICT technologies, such as 5G infrastructure, 
with the ICT market reaching around USD 36 billion in 2017 [1]. The number of Saudi users of Internet has increased significantly, as the Saudi government has provided Internet services in order to enable users to access ICT services adequately in 19,351 remote locations, including rural areas [1]. In addition, Saudi Arabia is ranked among the top countries in terms of ICT development — ranked 48th globally [2]. All these digital achievements in ICT services have led Saudi Arabia to be considered one of the world's most digitally connected countries under its Vision 2030.

These changes in ICT have made significant alterations in the way people work, communicate, and learn, and have had significant consequences in numerous fields, including (but not limited to) health, medicine, and education [3], [6]. One of the new developments as a result of integrating technologies in education is eLearning. eLearning has emerged as one of the rapidest trends in today's education, it becomes the foundation of online learning environment [4].

The eLearning environment significantly enables students' learning without distance and time constraints, giving them more opportunities to conduct their learning at their own pace. Recently, eLearning has begun to adopt several technologies to transform it into a more attractive learning environment for students, among which is the use of digital games [5].

The "Gamification" concept is gaining increasing attention among researchers [15]. Gamification is not related to games; it is just the use of game elements in a non-game situation. While the main purpose of these games is entertainment, it is widely accepted that there is a significant interest in harnessing their potential for educational purposes.

The use of games as a learning tool has been gaining prominence in recent years [3]. Digital games are likely to become the fastest growing eLearning method as playing digital games is widely considered the activity that pupils and even adults have preferred over many others [7]. The main purpose of playing games is normally entertainment, but their widespread applicability has given games additional roles in numerous aspects of daily life [8]. The increase in information transfer has made it difficult to deliver education to individuals, as rapid developments in the field of technological innovation require people to adjust quickly [5]. In the context of eLearning and games, several potential advantages of eLearning and digital games in education have been reported by several studies [9], [10], [11]. However, some issues have been reported as well regarding the importance of increasing motivation and engagement of eLearning users [3], [12]. Due to the above-mentioned issues, some researchers have begun to explore the positive aspects of digital games to non-gaming education settings, instead of using the games themselves in education. This approach, that could be employed in any situation, including education, is generally referred to as gamification [13].

Gamification is the use of game-design techniques and game elements in non-game contexts in order to increase user engagement and retention [14]. Gamification is an attractive and engaging tool when used appropriately. It could have potential impacts on the educational system, in which students' lack of motivation is well known. By assisting students in Saudi universities through enhancing motivation and engagement through implementing gamification in eLearning environments, it is highly possible that their quality of education via eLearning could be improved. However, there has 
been a deficiency of empirical research and practical evidence regarding the potential contribution of implementing gamification in learning [15].

The main goals of this research are to complete a state-of-the-art study of game design, game-based learning, and gamification in education concepts. Defining and analyzing some gamification frameworks in order to gamify eLearning experiences will also be discussed. Furthermore, the study aims to analyze the gaps in these frameworks in order to propose a conceptual framework based on the instructional design (ID) model.

In light of the aforementioned information, this research will contribute to the existing literature by taking a closer look at the concept of gamification in order to introduce a proposed conceptual framework to gamify eLearning systems based on ID models that contribute to the gamification design process. The current paper is organized according to the following sections:

a) the background of basic features about games, game-based learning, and gamification in education, and their results on the educational process

b) a framework of gamifying the eLearning experience

c) methodology used for the identification of successful strategies based on literature explaining gamification and game strategies to articulate the proposed gamification conceptual framework in eLearning system based on the ID model

d) the findings and discussion

e) finally, the conclusion and implications.

\section{$2 \quad$ Background}

\subsection{Games}

There are many recent definitions of games. Baranowski [54], for instance, claimed that playing games meets ongoing mental needs. A game is defined as a mental or physical contest according to specific objectives. Games are expected to become the main form of popular culture interaction in society [55]. Whether games are offline or online, they have assisted academics in obtaining their educational targets in a more attractive and engaging way [21], [22], [23]. Ryan Juraschka According to previous research, there is an increasing acknowledgement that any definition of "games" has to transcend the characteristics of the game itself and include situated constructive meaning.

Thus, the elements that belong to successful games should be addressed. A successful game's components are [20]: self-representations, three-dimensional environments, a narrative, feedback, reputations, rank and levels, markets and economies, competition under rules, teams, communication, and finally, time pressure. 


\subsection{Gamification}

The concept of gamification was originated in 2008 in the digital media industry, although it did not spread widely until 2010 [15]. Researchers have tried to define the concept of gamification, and accordingly several definitions have been developed [53]. These differences can be attributed to the emergence of several concepts which are potentially parallel or overlapping within the broader gamification framework. Gamification is defined as the usage of game-design techniques in non-game contexts (mainly consumer-oriented web and mobile web sites) to motivate some behavior and support the adaptation of the applications [8], [15], [24].

Similarly, gamification is defined by [53], [60] the use of game design elements in non-game settings. This differentiates it from digital games and design for playful interactions. Thus, any application, context, process, or task can hypothetically be gamified. In addition, educational games employ more game design knowledge, graphics, and resources, while gamification does not require special design or as many resources [8]. Regarding the identification of gamification elements, Deterding et al. (2011) [51] identified the following elements, as shown in Figure 1.

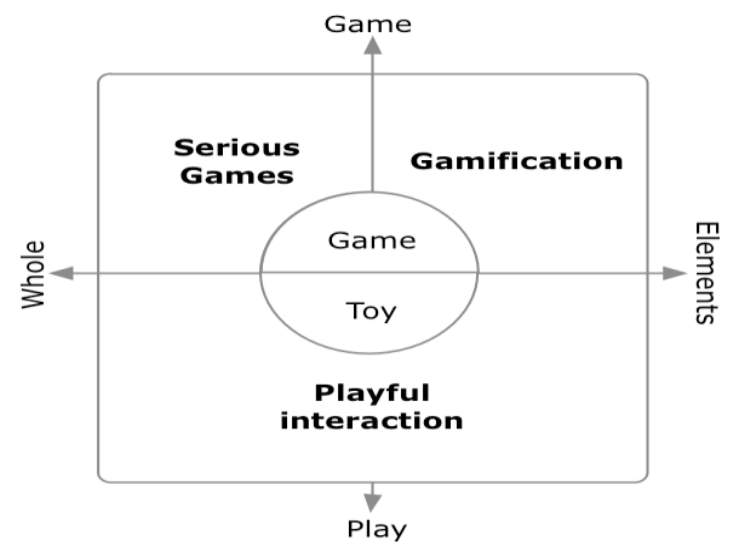

Fig. 1. Gamification Elements (adapted by Deterding, et al., 2011)

The components of gamification had their origin in self-determination theory, which relates to the internal psychological needs of self-development and the effect of the environment on individual motivation. These internal needs are competence, the need to exercise a sense of ability, and the need to win social interaction and afford relationships, communication, and independence. This happens through the individual's desire to possess the ability to make alternatives and move away from dependence on others [25], [26].

In general, gamification includes the following three components [27]:

Mechanics: This refers to the description of the game components according to the level of data representation and algorithms, which help the user interact with the game. The mechanisms of interaction can be identified as follows [28] [33], [34]: 
- Points, which refer to progress indicators to reward the user.

- Levels that deal with indicators of users reaching certain levels of attainment and enabling them to upgrade automatically.

- Challenges that include tasks that give the user the feeling that they are working toward a specific goal.

- Honor lists involve rankings used for competition purposes to display desired practices in order to induce specific behavior.

- Virtual goods, or tradable digital tokens, that make the game more effective by exchanging points.

- Feedback, which is correlated with a forum to engage users in the game.

Dynamics: This refers to the description of run-time behavior of mechanics that acts through player time. It seeks to fulfill needs and desires, including the desire of reward, self-expression, and competition. It includes the following human desires [28]:

1. Reward, which refers to earning points, promoting, or ordering goods

2. Status, which refers to promotion and the ability to compete

3. Achievements that deal with the challenge to accomplish difficult tasks

4. Self-expression that deals with the desire to express independence

5. Altruism that focuses on giving gifts to others as it is an action described as perceiving enjoyment and helping behavior

Aesthetics: This refers to the desirable emotional responses encouraged in each player when interacting within the system of the game, including fun, credibility, and surprise, as well as the game's appearance, color, diversity, and originality.

\subsection{Gamification in education}

Gamification has been an interesting topic since following the Gartner Hype Cycle of Technology over the past few years. This cycle is developed and used by the U.S "IT research and advisory". The purpose is to represent the adoption, maturity, and social application of technology [29]. Despite the significant growth in applying gamification to learning [30], there has been little research that examines the value of employing gamification in education and eLearning systems [8], [16].

Real-world digital games based on problem-solving scenarios are more attractive when they incorporate the technique of gamification. One prominent example is a game called Foldit. This game led to the crowd-sourced discovery of a key protein. This game attracted 46,000 participants who played the game over just 10 days and solved a mystery that scientists had been working to solve for approximately 15 years [31]. In another study, the authors proposed standardization games that implemented gamification in the design in order to overcome a serious problem, which was that many of the calibrations were unenjoyable and tedious [24]. As a result, the users realized that games were more fun and enjoyable than the regular calibration procedures. Another study was conducted to determine the efficiency of employing gamification on students' attitudes and interest. The results showed that using gamification can positively contribute to students' attitudes as they develop more agreeable feelings and 
have more enjoyable experiences in the learning process, compared to traditional approaches [49]. Accordingly, gamification for learning can be defined as how to use game-based mechanics, thinking, and aesthetics to engage and motivate learners to accomplish, hence, engage learning, and problem solving [32]. The main differences between the concepts of game, game-based learning, and gamification are summarized [35] in Table 1.

Table 1. The Differences between: Game, Game-Based Learning, and Gamification

\begin{tabular}{|l|l|l|}
\hline \multicolumn{1}{|c|}{ Game } & \multicolumn{1}{|c|}{ Game-based Learning } & \multicolumn{1}{c|}{ Gamification } \\
\hline $\begin{array}{l}\text { Games are just for fun, and may or } \\
\text { may not have defined rules \& } \\
\text { objectives. }\end{array}$ & $\begin{array}{l}\text { learning objectives are defined } \\
\text { within games }\end{array}$ & $\begin{array}{l}\text { Depends on collection of tasks } \\
\text { with points or reward. }\end{array}$ \\
\hline $\begin{array}{l}\text { Winning and losing is a part of the } \\
\text { game. }\end{array}$ & $\begin{array}{l}\text { The point is to motivate students to } \\
\text { act and learn as a result. }\end{array}$ & $\begin{array}{l}\text { The point is to motivate students to } \\
\text { act and do somewhat }\end{array}$ \\
\hline $\begin{array}{l}\text { Playing games comes first, rewards } \\
\text { are secondary }\end{array}$ & $\begin{array}{l}\text { Playing the game is essentially } \\
\text { rewarding }\end{array}$ & $\begin{array}{l}\text { Existence fundamentally rewarding } \\
\text { is non-compulsory }\end{array}$ \\
\hline $\begin{array}{l}\text { Games are generally secure and } \\
\text { expensive to design. }\end{array}$ & It is generally expensive to build & $\begin{array}{l}\text { Gamification is generally easier } \\
\text { and inexpensive }\end{array}$ \\
\hline $\begin{array}{l}\text { Stories and Scenes are portion of } \\
\text { the game }\end{array}$ & $\begin{array}{l}\text { Content is frequently transformed } \\
\text { to fit the story of the game }\end{array}$ & $\begin{array}{l}\text { Usually game-like topographies } \\
\text { are added to the learning } \\
\text { Management System (LMS) rather } \\
\text { than the content }\end{array}$ \\
\hline
\end{tabular}

\subsection{Gamifying e-learning experience: Framework review}

The following section illustrates the potential way that gamification can be applied in an e-course. The content structure of e-courses is normally linear, which means the content can be easily gamified [8]. A framework is a conceptual construction proposed to support as a guide in somewhat valuable [17]. Di Tommaso [36] defines the gamification framework for success in Figure 1.

\section{A FRAMEWORK FOR SUCCESS}

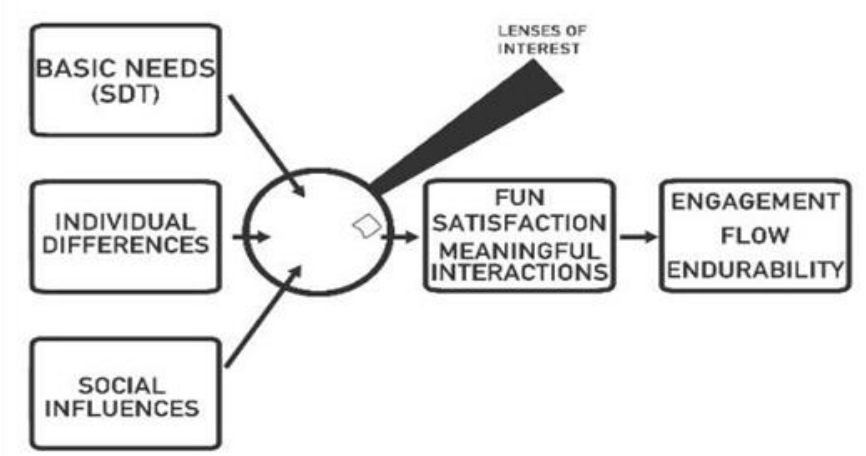

Fig. 2. Gamification framework for success (Adapted by Tommaso) 
The gamification framework consists of several steps. It starts with discovering the reason for gamification according to the objectives of stakeholders and businesses, and then continues by identifying profiles of the players and motivational users. Next, objectives are established, skills are tracked and measured, and lenses of interest are defined. Lastly, desired outputs are assessed, and it is play-tested and polished. The best-known design framework, known as 6-D, presents the following phases of gamification [37], as illustrated in Figure 2



Fig. 3. The "6-D" Gamification Framework

This framework starts with identification of the objectives, then proceeds to the targeted expected behaviors, labels the player's style, and plans the activity loops without forgetting fun as a critical factor. Finally, the gamification system is published with suitable tools. Kuutti [38] has added an additional three steps to the 6-D model, including a trial version launch, actual operation, and a follow-up for additional development, as illustrated in Figure 3

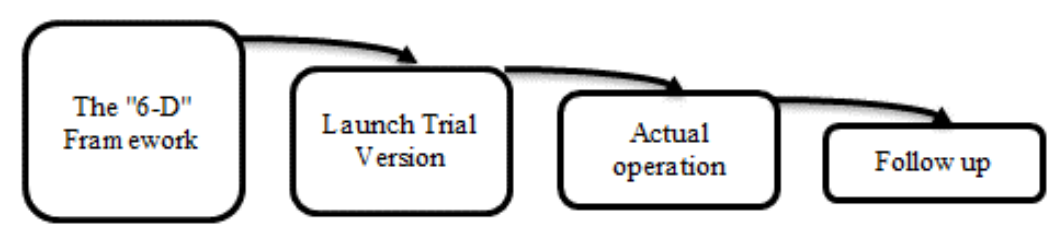

Fig. 4. . Octalysis Framework

There is another complete gamification framework called Octalysis [39]. Based on this framework, gamification refers to the design that focuses on the human motivation of the design process (Human-centered design). The framework is explained by the following octagonal figure, which involves eight ambitions represented by each side: calling, development, accomplishment, creativity, ownership, social influence, scarcity, and avoidance. See Figure 4. 


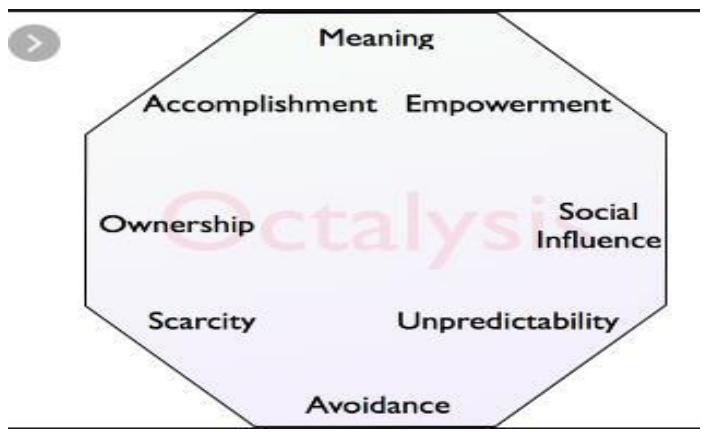

Fig. 5. Octalysis Framework.

Marache-Francisco and Brangier [40] defined the gamification design process based on Human-Computer Interaction (HCI) principles, as illustrated in Figure 5.

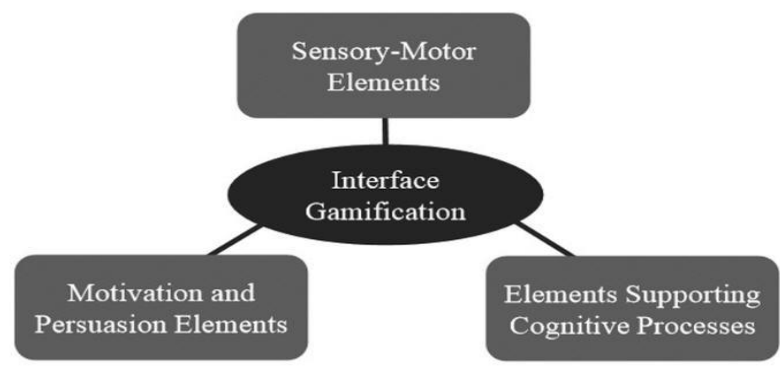

Fig. 6. Gamification Design Process.

The three dimensions of this model are a sensory-motor dimension, a motivation emotion, and a cognitive dimension of interaction. The main steps in the design process involved user-centered design and the gamification experience. Herzberg [41] described gamification development as a technology-centered design process. The purpose is to visualize how gamification is presented into an information system, starting from the business modeling and ending with the tracking and improvement stage.

This framework also reflected role definitions, such as end-user, gamification, domain, business, and IT specialists. The framework contained the following phases: business modeling, requirements, iterative design, provisioning, implementation, testing, deployment, and monitoring. Zichermann and Cunningham [34] identified the reasons for users' desire to play games to be enjoyment and to socialize. Regarding the categories of players, they were perceived as follows: the explorer, the achiever, the socializer, and the killer. For explorers, experience is the main objective. They like to go out into the world, take things back to their community, and then announce it, while achievers focus on achieving results in a competitive environment. However, socializers rely on playing games for the advantage of social interaction. Finally, killers are like achievers, but differ in that their desire is to win while the other should lose. 
A successful design of a gamified eLearning system should consider the main concept of games: goal-based activities, reward mechanisms, and progress tracking. In eLearning systems, learners are directed to assume certain tasks to achieve the desired outcomes. Thus, progress tracking and reward mechanisms can be used in eLearning to increase users' motivation and engagement [42]. All proposed models for introducing gamification in eLearning can be related to software design. Thus, it should follow all phases of eLearning system development: analysis, design, development, and evaluation, as displayed in Figure 6 [12], [43].

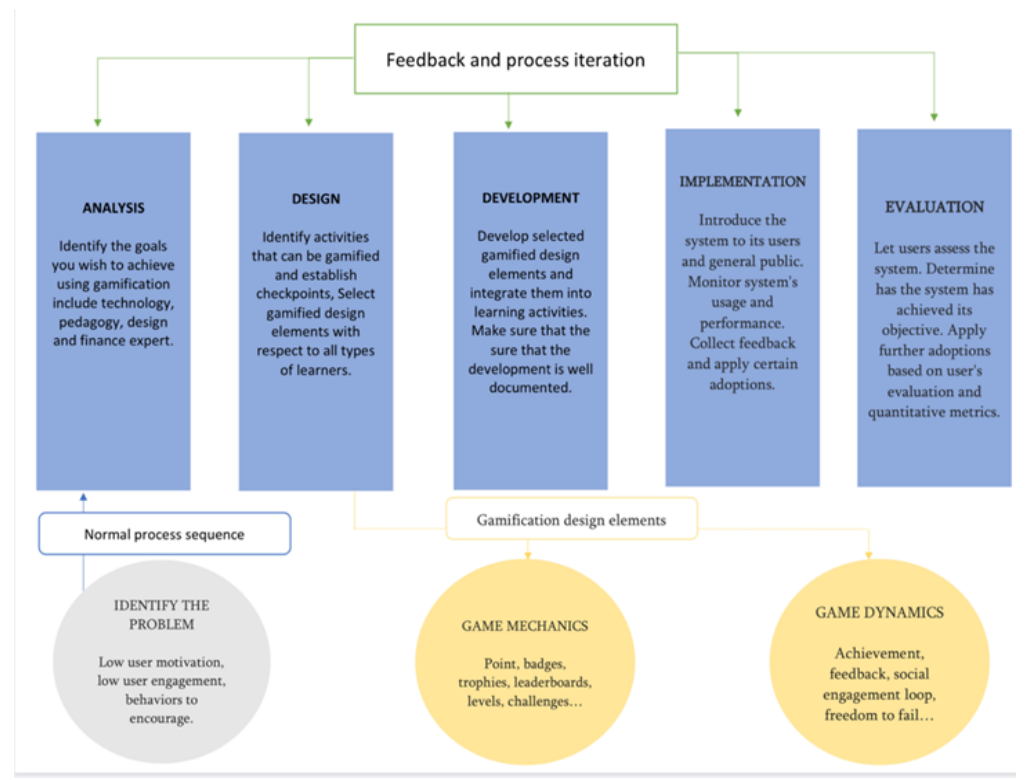

Fig. 7. Phases of presenting gamification within eLearning system

\section{Method / Approach}

The author reviewed the previous gamification frameworks, providing a summary that analyzed and explained each approach. Hence, by reviewing several of the instructional design models in the field of eLearning, the research method is conducted as follows:

\subsection{The proposed gamification conceptual framework in integrating with e- learning system}

In order to develop a gamification conceptual framework in eLearning systems, especially e-courses, the current paper has employed a system based on research and studies indexed in several databases, including Google Scholar, Web of Science (WOS), and Scopus, in addition to digital libraries such as IEEE Xplore, Springer, and 
Science Direct (Elsevier). Six gamification frameworks were reviewed and explained based on a summary of each approach. Hence, by reviewing several of the design models in the field of eLearning [44] - [48], the research process was conducted in two main phases:

- Analysis: By conducting a systematic literature review of research and studies regarding digital games, gamification, gamification frameworks, and gamification in eLearning.

- Design: A conceptual framework is proposed based on the works reviewed in the literature. The gamification framework to gamify eLearning courses is designed by taking into consideration the necessary producers in order to obtain more results that are constructive.

Thus, the research provides a framework for the integration of gamification in eLearning systems, as shown in Figure 7. The stages of the framework are as follows:



Fig. 8. Framework for gamification in e- learning at Saudi Arabia universities

Managerial process: This process controls the progress of the development stages and includes many activities, including project planning and controlling, team organization, quality assurance, selection of tools, and training. These activities are described as follows:

- Project planning and control: Planning includes setting a schedule that clarifies the timing of course development and arranging activities to be carried out by the development team, as well as determining the budget necessary for the development of courses and clarifying aspects of their distribution. The control process is concerned with setting a mechanism to follow the progress of course development according to a sequence of stages and to set the budget.

- Team organization: The development team includes content experts such as course teachers, media experts, and programmers, in addition to curriculum and teaching experts.

- Quality assurance: The methods and mechanisms of the review that are carried out at the end of each stage of development are determined to ensure that the e-course meets the quality standards for developing e-courses published on the web. 
- Tools selection: The tool of course site creation is determined; it may be a general tool such as an HTML (editor), which can be used in developing e-courses, or a ready-made course management system such as WebCT or Moodle. (Note: Blackboard is now used in Saudi Arabia universities as a learning management system).

- Training: This activity is concerned with developing the skills of the work team to ensure the effectiveness of their performance of the tasks assigned to them during the development process as well as mechanisms for training teachers and students in utilizing the course site.

\subsection{Analysis: This stage contains the following steps:}

1. Course Domain Analysis: This phase involves several tasks, including defining the study program and the goals of the program, determining the requirements for studying the course, and its relationship to other courses within the framework of the study program system.

2. Content Analysis: This involves defining the objectives of the course and defining the content and organizing it, while searching for sources related to the content.

3. Student Analysis: This involves defining the target group studying in the course, their cognitive characteristics, skills, and technical capabilities, as well as classifying the target group according to the player types: explorers, achievers, socializers, and killers.

4. Instructor Analysis: This refers to determining the characteristics of teachers and assessing their ability to understand the content of the subject and follow directions, their experience in distance teaching, their computer efficiency, their knowledge, and their experience with Internet services such as email and file transfer protocol (FTP) transfer .

5. Learning Environment Analysis: This involves specifying the communication technologies available in the learning environment, the hardware components, and the software programs available to students with specification of the characteristics of the natural and social environment and the time available to study the course.

6. Defining the Functional Requirements: This refers to determining the processes available to students and teachers, which can be divided into teaching and learning processes, including creating and updating course content, monitoring and assessing students, publishing materials across the web, and providing advertisements and instructions to students. Examples of learning processes include reading course information across the web, writing and inserting reports, tasks, and assignments, and listening to audio and video conferences.

7. Defining Interaction Requirements: The requirements of interaction are related to the ways in which students communicate with instructors, with each other, and with the content provided. In this step, the supported medium type is determined for each type of interaction available across the course, such as email, chat rooms, video conferences, and newsgroups.

8. Defining the Quality Attribute: The quality attributes are defined as follows: 
- Content attribute: Its comprehensiveness, the availability of feedback on tasks, the availability of easy and attractive ways to present the content, and a summary of allimportant ideas are presented.

- Structure attribute: The ease of navigating the course pages through organizing them into hierarchically linked pages in light of the presented content.

- Interface attribute: Organizing the display and distribution of links and different types of multimedia elements on the page in a way that does not cause distraction and confusion for the students.

- The gamification attribute: Reeves and Read [19] presented basic elements to produce a successful game design, including self-representations, 3-D environments, feedback, levels, marketplaces, competition under rules, teams, and communication.

\subsection{Design: The design stage contains the following steps}

1. Designing the structure of the web study guide: This guide is usually designed in a hierarchical form, where the main page is located at the top of the pyramid. This is displayed when the student connects to the course site. The page provides course title, name of the scientific section, name of the educational institution and its logo, and contains links to each level of the hierarchical organization. Figure (8) illustrates a proposed concept for the design of the web study guide

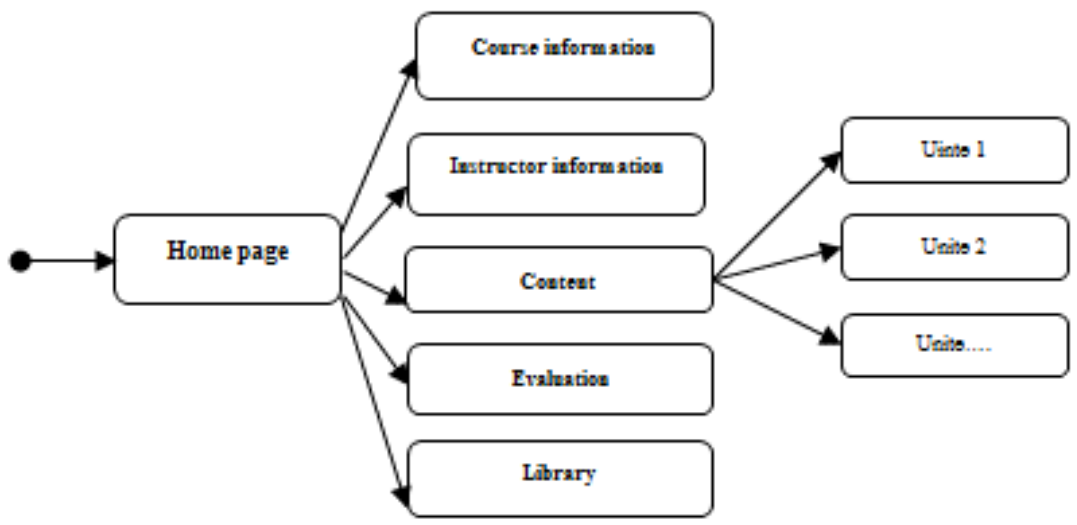

Fig. 9. Study Guide Perception

2. Designing the study guide content: This step is concerned with dividing the course content into successive units. A page called the unit page, in which the following tasks are performed, represents each unit:

a) Define the structure of the unite page: This step is concerned with the construction of the unite page. It defines the contents of the unit page that include each of the learning goals and addresses the unit topics, learning activities and evaluation. Figure (9) shows the construction of the unit page. 


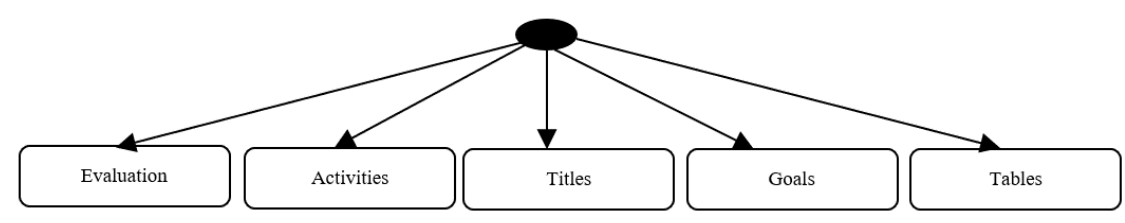

Fig. 10.The Unit Page Construction

The learning activities are significant components in the course as they explain what the learner must do in order to achieve the learning goals. Various aspects of design have been suggested for those elements [32], [33], [34], [42], [59]:

- Points reflect the practice of bonus points for revealing some additional content / awards or karma points for gaining status.

- Rewards and achievements (badges) are fun techniques where learners can share their awards and achievements.

- Learners should be given some customization options.

- Leaderboards should be supportive and active in a competitive environment. The use of social types of leaderboards should be considered.

- Easy starting levels enable progress tracking as it provides immediate feedback based on learners' progress.

- Rewards that motivate the learners for best implementation.

- Provide learners with feedback during the learning process.

- Using social engagement to motivate learners.

- Providing learners with independence to fail and provide them with positive instructional feedback.

a) Designing the presentation of the unit: Consider how to represent the contents of the unit page, which can be done in several ways, including menus or a surface view.

b) Designing the user interface: This step is concerned with the design of the user interface and includes a set of tasks, including designing the visual structure and navigation capability of the web page and the layout of each page of the course. The multimedia elements, data, and buttons on the page must be positioned. Also, the design of these elements themselves must be considered in detail, for example, in the design of a video component, the development team must determine its content, size, and degree of clarity.

\subsection{Development}

This stage aims to achieve the following tasks:

1. Producing the multimedia items and study material: In this step, multimedia elements are produced considering the cooperation between multimedia developers and content experts to produce the most efficient and effective production of these elements and study materials. 
2. Assembling the items and study material into the prototype: In this step, the multimedia elements and study materials that were produced in the previous step are collected in the prototype form using the site management tool.

3. Integrating components of the e-Course: In this step, the prototype of the e-course is ready to be uploaded to the course site by integrating the tools for interacting with the pages of the web study guide inside the web server. Blackboard has the necessary features to integrate web pages with interactivity tools.

4. Validating the web-based course: This step is concerned with testing the electronic course through a group of students and experts in the field of developing e-courses to determine whether the course complies with the quality standards previously identified in the second stage of the model. The result of that step is to adjust and refine the course before it is delivered to students.

\section{Implementation}

In this phase, the course site becomes ready for work, with the necessity of carrying out some tasks, including the production of a student guide that helps them identify the content of the course and how to deal with it. The students are trained in the skills of dealing with electronic courses, and in the use of available communication tools. An account is created for students to use the course site.

This phase indicates the end of the development process, the start of the operation process, and the maintenance of the course. This phase takes place once the system is presented to the user. It requires continuous review of the system's usage, as the goal is to achieve ideal system performance. It is also vital to gather feedback from learners and receive input about their specific needs. Implementation needs to take place rapidly for the different types of users, either faculty members, administrative staff, or learners. Implementation is one of the most important phases in eLearning and other web-based system development [43].

\section{$5 \quad$ Evaluation}

The users in this phase carry out an evaluation of the implemented system. In addition to responding to satisfaction surveys, there are numerous measurable metrics that can be used to investigate engagement of users: page views per visitor, time spent on-site, total time per user, visit frequency, and participation [8]. Based on the evaluation phase, the system and the objectives success will be assessed. Usability of an eLearning system can be recognized by certain mechanisms, including learnability, efficiency, memorability, errors, and satisfaction [; Z. Liu \& Z. Shaikh \& F. Gazizova 43].

\section{$6 \quad$ Findings and Discussion}

The findings of previous research on gamification studies in the field of education indicate that the general research on gamification suggests it has achieved implemented affordances and strong pedagogical outcomes (Deterding, et al., 2011; Keener, 2017; 
Al-Fatta et al., 2019; Majuri, 2018; Panis, et al., 2020; Liu et al., 2020) [51, 52, 53, 58, $59,60]$. Still, the pedagogical outcomes, particularly learning outcomes, did not proceed with the gamification design process principles or gamification integration with e-course. The current research pursued to examine alignment between design process and one of the ID models suggests the importance of developing an ID model as a basic feature when designing gamification within course structures, when compared to gamification research in other settings.

The practical capabilities and the various models for gamification and eLearning designs that were introduced by other researchers are reviewed as well. Many academics recognized the contribution of digital game components to education as a powerful benefit due to its impact on creating a motivational environment and enhancing the students' engagement. This research provided a conceptual framework to gamify eLearning courses.

In the framework of the previous studies, results of the study by Majuri et al. (2018) [58] indicated that gamification in education most generally employed affordances related to achievement and progression, whereas social and immersion affordances were much less public. Similarly, Vidakis et al. (2019) [57] identified gamification characteristics, such as score and rewards, that were employed to promote users' awareness and performance. However, the study by Al-Fatta et al. (2019) [53] dealt with the gamification concept separately from serious games, as it implemented game elements, not full-fledged games, into a non-game environment. It can be applied to web-based eLearning applications.

The proposed conceptual gamification framework provided an experience for students that eLearning courses should be evaluated. The gamification framework focused on the improvement of learners' motivation by collecting user feedback and information from system logs.

It recognized that the eLearning platform is a required environment used to control and conduct the desired experience. Gamification elements and design issues are addressed within the framework design. The major approaches considered when designing the framework are as follows: a user-centered approach, as users and their aims are the focus of the development; a game-centered approach, focusing on the game elements, components, and artifacts; and a technology-centered approach, focusing on the modeling and its design artifacts. However, despite the proposed gamification that focused on gamification principal and user-centered and technological approaches to gamification design, the theoretical framework still needed to be implemented in real eLearning courses in an experimental design. Motivational and psychological theories, in addition to focusing more on effective design principles, should be considered in this framework to ensure accurate results when gamifying the eLearning experience [59]. In terms of the results of the reviewed studies, a significant majority mainly reported positive outcomes with varying experiences [60].

As noted above, all the literature previously published in the gamification field was included in this research. In this paper, the term gamification was considered to act as an umbrella term for various kinds of gamified solutions in educational and learning contexts. The reviewed studies involved those on gamification, e.g. in higher education. In conclusion, this study differs from previous research works by proposing gamification elements and integrating them into an ID model to support a systematic conceptual framework for the eLearning environment, especially e-courses. 


\section{$7 \quad$ Conclusion and Implications}

Considering the previous conceptual frameworks for gamification in eLearning courses leads to numerous conclusions. Although it has some disadvantages, gamification offers positive features to inspire learners' performance and produce measurable feedback. Gamification, viewed as didactic games, is a subset of digital games. It is not practical to make everything into a competition or to force learners into a situation in which they are expected to collect points for each human change. It is necessary to take a systematic approach to the gamification of the eLearning experience, which considers inputs, processes, and outputs of the learning system based on the ID model.

The research implications are significant; the gamification design process, based on the ID model, can ensure students' engagement and implementation affordance in the eLearning environment, in terms of encouraging the active participation of and enjoyment by students.

Finally, for future work, qualitative and quantitative inputs should be collected in order to improve the current conceptual framework. Additionally, more research is needed to articulate the didactic changes between digital games, game-based learning, and gamification in education for a detailed investigation of the distinct phenomena by connecting it through different learning theories.

Furthermore, this research can be extended in the future by leading research about the types of users by studying the impact of employing different didactic approaches to learners' preferences and their knowledge when gamifying their eLearning experiences.

\section{References}

[1] The International Telecommunication Union (ITU), "Measuring the Information Society Report, Volume 2. ICT Country Profiles," International Telecommunication Union, 2018. Available: $\quad$ https://www.itu.int/en/ITU-D/Statistics/Documents/publications/misr2018/ MISR-2018-Vol-2-E.pdf . [Accessed Nov. 27, 2019]. https://doi.org/10.1787/9789264244 $\underline{047-37-e n}$

[2] Unified National Platform, "Saudi Arabia Jumps 16 Ranks in the Global Competitiveness Index in the Pillar of Communications and Information Technology," Unified National Platform,2019Available:https://www.my.gov.sa/wps/portal/snp/pages/news/newsDetails/C ONT-news-10102019\%202/!ut/p/z0/04_Sj9CPykssy0xPLMnMz0vMAfIjo8zivQIsTAwdD Qz9LQwCXQ0CnV0MfYyNQgwM_M30g1Pz9L30o_ArAppiVOTr7JuuH1WQWJKhm5 mXlq8f4ezvF6Kbl1perGtoYGhgZGBoqWCkX5DtHg4AN9U4xQ!!/ [Accessed Feb. 12, 2020].

[3] J. Simões, R. Redondo, and A. Vilas, "A social gamification framework for a K-6 learning platform," Computers in Human Behavior, vol. 29, pp. 345-353, 2013. https://doi.org/10. 1016/j.chb.2012.06.007

[4] Y. Khlifi, Y. and H. A. El-Sabagh, "A novel authentication scheme for e-assessments based on student behavior over e-learning platform", International Journal of Emerging Technologies in Learning (iJET), 12 (4), April. 2017. pp. 62-89. https://online-journals. org/index.php/i-jet/article/view/6478/4372 . [Accessed Sep. 08, 2019]. https://doi.org/10. 3991/ijet.v12i04.6478

[5] H. Yamani, "E-learning and digital games: The potential contributions to mathematics education in Saudi Arabia", PhD thesis, La Trobe university, Melbourne, Australia, 2014. 
[6] E. Klopfer, S. Osterweil, J. Groff, and J. Haas, "Using the technology of today in the classroom today: The instructional power of digital games, social networking, simulations and how teachers can leverage them, The Education Arcade 1; Massachusetts Institute of Technology, 2009: pp, 20, Available: https://www.researchgate.net/publication/2631259 41_ [Accessed May 14, 2019].

[7] P. Wouters, E. van der Spek, and H. van Oostendorp, "Current Practices in Serious Game Research: A review from a learning outcomes perspective," in Games-based learning advancements for multi-sensory human computer interfaces: Techniques and effective practices, T. M. Connolly, M. Stansfield, \& L. Boyle, Eds. Hershey, PA: IGI Global, 2009, pp. 232-255. https://doi.org/10.4018/978-1-60566-360-9.ch014

[8] C. Muntean, "Raising engagement in e-learning through gamification," In Proc. The 6th International Conference on Virtual Learning ICVL, Cluj-Napoca, Romania, 2011. vol. 1, pp. 323-429.

[9] L. Annetta, J, Mangrum, S, Holmes, K. Collazo, and M. Cheng, "Bridging realty to virtual reality: Investigating gender effect and student engagement on learning through video game play in an elementary school classroom," International Journal of Science Education, vol. 31, no 8, pp. 1091-1113, 2009. https://doi.org/10.1080/09500690801968656

[10] J. Barojas, and J. Vázquez, "Teachers as architects of knowledge in e-learning," In Proc. Computers and Advanced Technology in Education 'Cancun, Mexico, 2002, pp. 20-22.

[11] M. Kebritchi, A. Hirumi, and H. Bai, "The effects of modern mathematics computer games on mathematics achievement and class motivation," Computers \& Education, vol. 55, no .2, pp. 427-443, 2010. https://doi.org/10.1016/j.compedu.2010.02.007

[12] O. Wongso, Y. Rosmansyah, and Y. Bandung, "Gamification framework model, based on social engagement in e-learning 2.0," In Proc. The 2nd International Conference on Technology, Informatics, Management, Engineering and Environment, Aug. 19-21, Bandung, IEEE Xplore Press, pp. 10-14, 2014. https://doi.org/10.1109/time-e.2014.7011583

[13] A. Domínguez, J. Saenz-de-Navarrete, L. De-Marcos, L. Fernández-Sanz, C. Pagés, and J. Martínez-Herráiz, "Gamifying learning experiences: Practical implications and outcomes," Computers \& Education, vol. 63, pp. 380-392, 2013. https://doi.org/10.1016/j.compedu.20 $\underline{12.12 .020}$

[14] L. De-Marcos, A. Domínguez, J. Saenz-de-Navarrete C. Pagés, "An empirical study comparing gamification and social networking on e-learning,". Computers \& Education, vol. 75, pp. 82-91, 2014. https://doi.org/10.1016/j.compedu.2014.01.012

[15] S. Deterding, D. Dixon, R. Khaled, and L.Nacke, "From Game Design Elements to Gamefulness: Defining Gamification," In Proc. The 15th International Academic MindTrek Conference: Envisioning future media environments, Tampere, Finland: ACM Press, 2011, pp. 9-15. https://doi.org/10.1145/2181037.2181040

[16] K. Sonts, "Gamification in Higher Education: The Case Study on the "Game Interactions Course,"M.S. Thesis, Tallinn University Institute of Informatics, Tallinn, Estonia, 2013.

[17] A. Mora, D. Riera, C. González, and J. Arnedo-Moreno,"A Literature Review of Gamification Design Frameworks," In Proc. The 7th International Conference on Games and Virtual Worlds for Serious Applications (VS-Games), Spain, 2015, pp. 1-8. https://doi. org/10.1109/vs-games.2015.7295760

[18] J. Juul, Half-real: video games between real rules and fictional worlds. Cambridge: MIT Press, 2011

[19] Entertainment Software Association (ESA), "Essential facts about computer and video game industry," Entertainment Software Association, 2015. Available: https://www.theesa. com/wp-content/uploads/2019/05/ESA_Essential_facts_2019_final.pdf . [Accessed April $11,2020]$.

[20] B. Reeves, and J. L. Read, Total Engagement: How Games and Virtual worlds are Changing the Way People Work and Business Compete. Boston: Harvard Business reviews Press, 2009. 
[21] A. McFarlane, A. Sparrowhawk, and Y. Heald, Report on the Educational Use of Games. TEEM (Teachers evaluating educational multimedia), Cambridge.

[22] B. Gros, "Digital Games in Education: The Design of Game-Based Learning Environments," Journal of Research on Technology in Education, vol. 40, no. 11, pp.23-38, 2007. https://doi.org/10.1080/15391523.2007.10782494

[23] R. Juraschkia,"How Digital Game-Based Learning Improves Student Success," Prodigy, September, 29, 2019. Available: https://www.prodigygame.com/blog/digital-game-basedlearning/ [Accessed March 03, 2020].

[24] D. Flatla, C. Gutwin, L. Nacke, S. Bateman, and R. Mandryk, "Calibration Games: Making Calibration Tasks Enjoyable by Adding Motivating Game Elements," In Proc. The 24th Annual ACM Symposium on User Interface Software and Technology, Californi: Santa Barbara, 2011. https://doi.org/10.1145/2047196.2047248

[25] M. Abosaif, "A proposed framework for using gamification in marketing universities services in Egypt," Journal of Educational Sciences, vol. 25, no. 2, pp. 364 -438, 2017.

[26] E. Deci, and R. Rayan, Handbook of self- determination research. Rochester, NY: University of Rochester Press, 2002.

[27] R. Hunicke, M. Leblance, and R. Zubek, "MDA; A Formal Approach to Game Design and Game Research," In Proc. The AAAI Workshop on Challenges in Game AI, Vol. 4, No. 1, 2004, pp. 1722.

[28] Bunchball, "Gamification 101: An Introduction to Game Dynamic to influence behavior," Bunchball, 2018. Available: http://jndglobal.com/wp-content/uploads/2011/05/gamifica tion1011.pdf . [Accessed Jan. 25, 2020].

[29] G. Gartner, Hype Cycle for Emerging Technologies Maps Out Evolving Relationship between Humans and Machines. Press Release, Stamford, Connecticut, 2013.

[30] K. Kapp, "Predictions For E-Learning", eLearning Magazine, 2011. Available: http://el earnmag.acm.org/featured.cfm?aid=1925057 . [Accessed April. 15, 2019].

[31] J. Anderson, and L. Rainie, "The Future of Gamification," Pew Research Centre Report, May. 18, 2012. Available: https://www.pewresearch.org/internet/2012/05/18/the-future-ofgamification/ . [Accessed Feb. 18, 2019].

[32] K. Kapp, The Gamification of Learning and Instruction: Game-Based Methods and Strategies for Training and Education, 1st Edition, San Francisco,CA: John Wiley and Sons, 2012.

[33] B. Enders, "Gamification, games and learning: What managers and practitioners need to know," The e-learning Guild Research, 2013. [Online]. Available: https://dharmamonk. files.wordpress.com/2014/01/guildresearch_gamification2013.pdf .

[34] G. Zichermann, and C. Cunningham, "Gamification by Design: Implementing Game Mechanics in Web and Mobile Apps". 1st Edition, Champaign, USA, O'Reilly Media, Inc, 2011.

[35] P. Thanekar, "Games vs Game-based Learning vs Gamification," Upside learning blog, May. 21, 2015. Available: https://www.upsidelearning.com/blog/index.php/2015/05/21/ games-vs-game-based-learning-vs-gamification/ [Accessed Aug. 22, 2019]. https://doi. org/10.1109/vs-games.2013.6624219

[36] D. Di Tommaso, "Beyond gamification: Architecting engagement through game design thinking," SlideShare, November. 11, 2011. .Available: https://www.slideshare.net/Di Tommaso/beyond-gamification-architecting-engagement-through-game-designthinking/48-STEP 1 WHY GAMIFY CRITICAL\%5bAccess . [Accessed Aug. 13, 2018].

[37] K. Werbach, and D. Hunter, "For the win: How Game Thinking Can Revolutionize Your Business", Washington, Wharton Digital Press, 2012.

[38] J. Kuutti,"Designing Gamification," M.S. thesis, Oulu Business School, University of Oulu, 2013. 
[39] Yu.-kai, Chou, "Octalysis: Complete gamification framework," 2013. [Online]. Available: https://yukaichou.com/gamification-examples/octalysis-complete-gamification-framework/ . [Accessed Sep. 08, 2019]. https://doi.org/10.17345/rio18.137-144

[40] C. Marache-Francisco, and E. Brangier, "Process of gamification. fom the consideration of gamification to its practical implementation," In Proc. The Sixth International Conference on Advances in Human oriented and Personalized Mechanisms, Technologies, and Services, Venice, Italy, 2013.

[41] P. Herzberg, "Gamification as a Services", PhD Dissertation, Faculty of Computer Science, Technische Universität Dresden, 2014.

[42] I. Glover, "Play as you learn: Gamification as a technique for motivating learners," In Proc. The World Conference on Educational Multimedia, Hypermedia and Telecommunications, (MHT’ 13), AACE, pp. 1999-2008, 2013.

[43] M. Urh, G. Vukovic, E. Jereb, and R. Pintar, "The model for introduction of gamification into elearning in higher Education", Procedia-Social and Behavior science, vol. 197, pp. 388-397, 2015. https://doi.org/10.1016/j.sbspro.2015.07.154

[44] C. Yu, A. Jannasch-Pennell, S. Di Gangi, and R. Wijesuriya, "Collaborative design and implementation of a large university's web-based course", In Pro. The National Convention of the Association for Educational Communications and Technology, October 25-28, Denver, CO., 2000.

[45] J. Montiva ,B. Sandia , J. Barrios, "Developing Instructional Web Sites - A Software Engineering Approach, Education and Information Technologies, vol. 7, no. 3, pp. 201-226, 2002.

[46] L. Comb, "Planning for E-Course Success", In Proc. ED-MEDIA 2001 World Conference on Educational Multimedia, Hypermedia \& Telecommunications, June 25-30, Tampere, Finland, 2001.

[47] C. Nam, and T. Smith-Jackson, "Web-Based learning Environment: A theory Based Design process for Development and Evaluation," Journal of Information Technology Education: Research, 6 (1), pp. 23-43, 2007. https://doi.org/10.28945/200

[48] E. Zaher, E-courses. Its design - Its Production - Its Publishing - Its Applying - Its evaluation, Alam elkotob. Cairo,2009.

[49] S. Papadakis, and M. Kalogiannakis, "Using gamification for supporting an introductory programming course: The case of class craft in a secondary education classroom," In Interactivity, game creation, design, learning, and innovation, 2017, pp. 366-375. https:// doi.org/10.1007/978-3-319-76908-0_35

[50] A. Carreño,"A framework for Agile design of Personalized Gamification Services". PhD. dissertation, Department of Computer Science, Multimedia and Telecommunications, Universitat Oberta de Catalunya, 2018.

[51] S. Deterding, R. Khaled, L. Nacke, and D. Dixon. Gamification: Toward a Definition, CHI 2011, May 7-12, 2011, Vancouver, BC, Canada. ACM 978-1-4503-0268-5/11/05.

[52] C. Keener. Instructional Design Talks to Game Design. On the Horizon. 25, 2017, 00-00. 10.1108/OTH-10-2016-0052.

[53] H. Al Fatta, Z. Maksom, and M. Zakaria, Game-based Learning and Gamification: Searching for Definitions. International Journal of Simulation: Systems, Science \& Technology. 19, 2019, 10.5013/IJSSST.a.19.06.41. https://doi.org/10.5013/ijssst.a.19.06. $\underline{41}$

[54] T. Baranowski, R. Buday, FAIA, D. I. Thompson, and J. Baranowski, "Playing for Real: Video Games and Stories for Health-Related Behavior Change," Am J Prev Med, 34, (1), pp. 74- 82, 2008. https://doi.org/10.1016/j.amepre.2007.09.027

[55] S. Papadakis, Evaluating A game-development approach to teach introductory programming concepts in secondary education. International Journal of Technology Enhanced Learning, 2020, $1.110 .1504 /$ IJTEL.2020.10024287. $\quad$ https://doi.org/10.1504/ ijtel.2020.10024287 
[56] S. Papadakis, A. Trampas, K. Barianos, M. Kalogiannakis, and N. Vidakis (2020). Evaluating the Learning Process: The "ThimelEdu" Educational Game Case Study. 290298. 10.5220/0009379902900298. https://doi.org/10.5220/0009379902900298

[57] N. Vidakis, K. Barianos, A. Trampas, S. Papadakis, M. Kalogiannakis, and V. Kostas (2019). "Generating education in-game data: The Case of an ancient theatre serious game". 10.5220/0007810800360043 . https://doi.org/10.5220/0007810800360043

[58] J. Majuri, J. Koivisto, and J. Hamari, "Gamification of Education and Learning: A review of Empirical Literature", Proceedings of the 2nd International GamiFIN Conference (GamiFIN 2018), 2018, pp. 11-19. Eds. by Koivisto J. \& Hamari J. CEUR Workshop Proceedings, vol 2186. CEUR-WS. ISSN: 1613-0073. Available: http://ceur-ws.org/Vol2186/paper2.pdf . [Accessed Jun. 22, 2020]. https://doi.org/10.1109/hicss.2014.377

[59] I. Panis, P. Setyosari, D. Kuswandi, and L. Yuliati. "Design gamification models in higher education: A study in Indonesia". International Journal of Emerging Technologies in Learning (iJET), 2020. 15. 244. 10.3991/ijet.v15i12.13965. Available: https://www.onlinejournals.org/index.php/i-jet/article/view/13965 . [Accessed Aug. 10, 2020]. https://doi.org/ 10.3991/ijet.v15i12.13965

[60] Z. Liu, Z. Shaikh and F. Gazizova, "Using the concept of game-based learning in education", International Journal of Emerging Technologies in Learning (iJET). 15(14), 2020. 10.3991/ijet.v15i14.14675, $\quad$ https://www.online-journals.org/index.php/i-jet/article/ view/14675/0 . [Accessed Sep. 13, 2020] https://doi.org/10.3991/ijet.v15i14.14675

\section{$9 \quad$ Author}

Dr. Hanaa Abdulraheem Yamani works as an Assistant professor of eLearning in Information Science Department of Umm Al-Qura University in Makkah of, KSA. Hayamani@uqu.edu.sa

Article submitted 2020-05-22. Resubmitted 2020-10-07. Final acceptance 2020-10-07. Final version published as submitted by the authors. 